\title{
Análise imuno-histoquímica de cães naturalmente infectados pelo parvovírus canino ${ }^{1}$
}

\author{
Eduardo C. Oliveira², Caroline A. Pescador², Luciana Sonne², Saulo P. \\ Pavarini $^{2}$, Adriana S. Santos ${ }^{2}$, Luís G. Corbellini ${ }^{3}$ e David Driemeier ${ }^{2 *}$
}

\begin{abstract}
Oliveira E.C., Pescador C.A., Sonne L., Pavarini S.P., Santos A.S., Corbellini L.G. \& Driemeier D. 2009. [Immunohistochemical analysis of dogs infected naturally by canine parvovirus.] Análise imuno-histoquímica de cães naturalmente infectados pelo parvovírus canino. Pesquisa Veterinária Brasileira 29(2):131-136. Setor de Patologia Veterinária, Faculdade de Veterinária, Universidade Federal do Rio Grande do Sul, Av. Bento Gonçalves 9090, Porto Alegre, RS 91540-000, Brazil. E-mail: davetpat@ufrgs.br

Ninety-six dogs with gross lesions suggestive of canine parvovirus infection were selected and necropsied in the Faculty of Veterinary Medicine, Universidade Federal do Rio Grande do Sul, between March 2005 and November 2006. The main gross lesions were enlargement of the Peyer's patches in the small intestine and hyperemia in the intestinal mucosa and serosa. Microscopically, the small intestine showed necrotizing enteritis in $77 \%$ (74/96) of the dogs examined. However, in $17.7 \%$ of the histological evaluation in the small intestine were damaged due to autolytic changes making it difficult to obtain an appropriate interpretation. The immunohistochemistry test was performed in tissues of small intestine, mesenteric lymph nodes, thymus, spleen, tonsils, tongue, and bone marrow in all the 96 selected cases. Parvovirus antigen was detected in $91.6 \%$ (88/ 96) of the dogs necropsied. The best result of the IHC test was seen in samples of small intestine which was positive in $77 \%$ (74/96) of the cases. The statistical analysis (Fisher test) showed a weak association between intestinal autolysis and positive result of the IHC test. The chance of the autolysed intestine showing a positive result in the immunohistochemistry test was 0.33 less $(\mathrm{OR}=0.33,95 \% \mathrm{Cl}: 0.10-1.17)$ when compared with small intestine not autolysed.
\end{abstract}

INDEX TERMS: Canine parvovirus, dogs, immunohistochemistry, small intestine, lymphoid tissue.

RESUMO.- Noventa e seis cães com lesões macroscópicas sugestivas de parvovirose canina foram necropsiados no Setor de Patologia Veterinária da Universidade Federal do Rio Grande do Sul no período de março de 2005 a novembro de 2006. Tecidos destes caninos foram analisados através de histologia e imuno-histoquímica. Aumento das placas de Peyer do intestino delgado e hiperemia da mucosa e serosa intestinal foram os acha-

\footnotetext{
${ }^{1}$ Recebido em 16 de novembro de 2007.

Aceito para publicação em 7 de novembro de 2008.

2 Setor de Patologia Veterinária, Faculdade de Veterinária, Universidade Federal do Rio Grande do Sul (UFRGS), Av. Bento Gonçalves 9090, Porto Alegre, RS 91540-000, Brasil. *Autor para correspondência: davetpat@ufrgs.br

${ }^{3}$ Departamento de Medicina Veterinária Preventiva, Faculdade de Veterinária, UFRGS, Porto Alegre, RS.
}

dos macroscópicos mais observados. Microscopicamente, foi visualizada enterite necrótica em $77 \%$ dos cães. Em 17,7\% as alterações histológicas do intestino delgado ficaram prejudicadas pela autólise, dificultando a interpretação. O teste de imuno-histoquímica em cortes de intestino delgado, linfonodo mesentérico, timo, baço, tonsila, língua e medula óssea de todos os 96 casos, foi positivo em $91,6 \%$ (88/96) dos casos. O intestino delgado demonstrou o melhor resultado, obtendo-se marcações em $77 \%$ (74/96) dos casos. A análise final do exame paramétrico de Fisher demonstrou uma fraca associação entre autólise intestinal e resultado positivo da imuno-histoquímica onde as chances de um intestino delgado autolisado histologicamente apresentar resultado positivo na imuno-histoquímica é 0,33 vezes menor ( $O R=0,33$; 95\% IC: $0,10-1,17)$ quando comparada a um intestino delgado não autolisado. 
TERMOS DE INDEXAÇÃO: Parvovírus canino, cães, imunohistoquímica, intestino delgado, tecido linfóide.

\section{INTRODUÇÃO}

O parvovírus canino (CPV, canine parvovirus) é um vírus pequeno (20-25nm), formado por uma única cadeia de DNA, de simetria icosaédrica, não envelopado e muito resistente a fatores ambientais e substâncias químicas (Jones et al. 2000). A parvovirose canina atinge principalmente cães entre 6 semanas a 6 meses de idade (McCaw \& Hoskins 2006). Os principais sinais clínicos apresentados são: vômito, diarréia intensa, apatia, anorexia, febre e em grande parte dos casos ocasiona a morte do cão dentro de curto período (Mason et al. 1987). O primeiro diagnóstico realizado no Brasil ocorreu em 1979 em um cão com gastroenterite hemorrágica (Hagiwara et al. 1980), e desde então o parvovírus canino é considerado como um dos principais agentes infecciosos de cães.

O diagnóstico post-mortem dos cães acometidos pela parvovirose canina é realizado com base nos achados macroscópicos observados na necropsia e lesões histológicas características (Hoskins 1997). O vírus atinge principalmente células com alta taxa de mitose, por isto as células linfóides e o epitélio do intestino delgado são os tecidos mais atingidos (Pletcher et al. 1979, Zee \& MacLachlan 2004). Com a presença do CPV nestes locais, rarefação linfóide e atrofia de vilosidades intestinais são identificadas como conseqüência da necrose (Macartney et al. 1984a).

As alterações macroscópicas nem sempre são comprovadas pela histologia. Os achados histopatológicos podem ser inespecíficos ou são prejudicados por autólise, principalmente no intestino delgado onde esta alteração post-mortem se apresenta precocemente (Ramos-Vara et al. 1999, Svara et al. 2003). Desta forma, métodos de diagnósticos auxiliares são necessários para a confirmação da parvovirose canina. A detecção do parvovírus canino através do teste de imuno-histoquímica é considerada útil no diagnóstico complementar, com a utilização em diversas pesquisas sobre o assunto (Macartney et al. 1984b, Carman \& Povey 1985, Agungpriyono et al. 1999). O objetivo do presente trabalho foi detectar o padrão de distribuição do parvovírus em diversos órgãos de cães infectados através da imuno-histoquímica e verificar se a autólise intestinal interfere de forma negativa no diagnóstico definitivo desta enfermidade.

\section{MATERIAL E MÉTODOS}

Durante o período de março de 2005 a novembro de 2006 foram selecionados casos com achados macroscópicos e microscópicos sugestivos de parvovirose canina, nos quais as necropsias, com coleta sistemática de órgãos selecionados, foram realizadas no Setor de Patologia Veterinária da UFRGS (SPV-UFRGS) para posterior diagnóstico de CPV pela técnica de imuno-histoquímica. Durante as necropsias, foram considerados como achados sugestivos de parvovirose canina a hiperemia intestinal acompanhada de aumento de placas de
Peyer, atrofia do timo e aumento de linfonodos mesentéricos (Meunier et al. 1981). Fragmentos do intestino delgado, baço, linfonodos mesentéricos, tonsila, timo, medula óssea e língua foram coletados, fixados durante 24 horas em formalina $10 \%$, processados posteriormente pelas técnicas histológicas de rotina e coradas pela hematoxilina e eosina. Dados referentes à idade, sexo e raça dos animais necropsiados foram devidamente registrados. Os casos foram selecionados mediante a observação de lesões histológicas caracterizadas por enterite necrótica e/ou rarefação de órgãos linfóides (Appel et al. 1979). Cortes histológicos de intestino delgado, linfonodo mesentérico, baço, timo, medula óssea, tonsila e língua foram submetidos a imuno-histoquímica pelo método streptavidina-biotinaperoxidase. A recuperação antigênica foi realizada com protease XVI (Sigma) durante 15 minutos. Como anticorpo primário, utilizou-se anticorpo monoclonal anti-parvovírus (MCA 2064Serotec) na diluição de 1:1000 durante 14-16 horas (overnight) na temperatura de $4^{\circ} \mathrm{C}$. Posteriormente, utilizou-se anticorpo secundário biotinalado conjugado a streptavidina (kit LSAB, Dako) durante o período total de 40 minutos. Para revelação utilizou-se DAB (3,3'-diaminobenzidina, Dako) como cromógeno por 10 minutos. Controles positivos foram inseridos simultaneamente com as lâminas testadas e consistiam de casos positivos testados previamente.

A análise estatística foi realizada para determinar a razão de chances (Odds ratio) de positividade por órgãos, verificando quanto um órgão é superior na performance da imunohistoquímica. A associação entre a autólise do intestino delgado e o resultado obtido na imuno-histoquímica deste órgão foi analisada pelo teste exato de Fisher. A seguinte fórmula para o cálculo da razão de chances foi utilizada:

$$
\begin{gathered}
\frac{p(1-q)}{q(1-p)} \\
p=\text { freqüência do primeiro grupo (IHQ positiva) } \\
q=\text { freqüência do segundo grupo (IHQ negativa) }
\end{gathered}
$$

\section{RESULTADOS}

\section{Dados gerais}

Durante o período de março de 2005 a novembro de 2006 foram necropsiados 1002 cães no Setor de Patologia Veterinária da UFRGS. Neste período, identificaramse 103 caninos ( $10,3 \%$ dos cães necropsiados) com achados patológicos sugestivos de parvovirose canina. Destes cães, 96 cães foram selecionados para a realização do estudo. A idade dos cães necropsiados variou de 30 dias a 11 meses (média $=3,32 \pm 1,9$ meses). Entre os cães analisados, $31,25 \%$ eram sem raça definida (SRD), Poodles corresponderam a $12,5 \%$ dos animais necropsiados, $10,4 \%$ eram Rottweiler e $6,25 \%$ da raça Shih-Tzu. A distribuição por sexo demonstrou que $54 \%$ eram fêmeas e $46 \%$ dos caninos eram machos.

\section{Achados patológicos}

Durante o exame macroscópico dos cães, as lesões mais observadas foram o aumento e depressão de placas de Peyer $(86,4 \%)$, hiperemia da serosa e/ou mucosa do intestino delgado $(85,4 \%$ ) e aumento de linfonodos mesentéricos $(82,3 \%)$. Outros achados patológicos identificados durante as necropsias foram: atrofia do timo, diarréia, con- 
teúdo hemorrágico na luz intestinal, fibrina aderida na mucosa do intestino delgado e esplenomegalia. A análise microscópica de órgãos linfóides revelou rarefação linfóide em grande parte dos casos analisados, acompanhada em alguns casos por hiperplasia de folículos linfóides, focos de hemorragia e congestão. No intestino delgado, enterite necrótica e rarefação de placas de Peyer foram as principais alterações observadas. Em $17,7 \%$ dos animais necropsiados, autólise foi identificada no epitélio intestinal. Freqüência das lesões histológicas dos órgãos linfóides e do intestino delgado estão apresentadas no Quadro 1.

\section{Quadro 1. Freqüência das lesões histológicas em cada órgão analisado nos 96 cães com parvovirose canina necropsiados no SPV-UFRGS}

\begin{tabular}{lcc}
\hline \multicolumn{1}{c}{ Órgão } & Freqüência (\%) & Lesão \\
\hline Tonsila & $91 / 92(98,9)$ & Rarefação linfóide \\
Timo & $91 / 94(96,8)$ & Rarefção linfóide \\
Baço & $92 / 96(95,8)$ & Rarefção linfóide \\
Medula óssea & $72 / 91(79,1)$ & Rarefação linfóide \\
Intestino delgado & $71 / 96(73,9)$ & Necrose do epitélio \\
& $58 / 84(69,0)$ & Rarefação linfóide \\
& & de placa de Peyer \\
Linfonodo mesentérico & $61 / 96(63,5)$ & Rarefação linfóide
\end{tabular}

\section{Resultados imuno-histoquímicos}

Resultado imuno-histoquímico positivo para CPV foi obtido em $91,6 \%$ (88/96) dos animais testados. Entre os órgãos analisados, o intestino delgado apresentou o meIhor resultado. Marcações positivas foram obtidas em $77 \%$ (74/96) dos segmentos intestinais. Um número maior de células positivas para CPV foi visualizado na base das vilosidades e em células descamadas do epitélio intestinal com grau de marcação geralmente de moderado a acentuado (Fig.1 e 2). Os resultados apresentados pela imuno-histoquímico sobre o total de casos analisados estão representados no Quadro 2. O epitélio escamoso estratificado da tonsila $(65 / 96)$ foi 0 segundo melhor órgão no estudo, obtendo-se a identificação viral principalmente em células basais da tonsila (Fig.3). Adicionalmente, uma fraca marcação nas células do tecido linfóide da tonsila foi observada em $52,2 \%$

Quadro 2. Freqüência de detecção de CPV em diferentes órgãos através do teste imuno-histoquímico realizado nos 96 caninos que apresentaram lesões sugestivas de parvovirose canina

\begin{tabular}{lcc}
\hline \multicolumn{1}{c}{ Órgãos testados } & $\begin{array}{c}\text { Imuno- } \\
\text { histoquímica } \\
\text { positiva }\end{array}$ & $\begin{array}{c}\text { Número de } \\
\text { animais } \\
\text { testados }\end{array}$ \\
\hline Intestino delgado & $77,1 \%$ & 96 \\
Tonsila epitelial & $70,6 \%$ & 92 \\
Língua & $68,9 \%$ & 45 \\
Linfonodo mesentérico & $62,5 \%$ & 96 \\
Tonsila linfóide & $52,2 \%$ & 92 \\
Medula óssea & $51,6 \%$ & 91 \\
Placas de Peyer & $45,2 \%$ & 84 \\
Timo & $44,7 \%$ & 94 \\
Baço & $43,7 \%$ & 96
\end{tabular}

dos casos analisados. Em 46,9\% dos cães do estudo foram avaliados quanto à presença do CPV na língua. Marcações de diferentes graus foram obtidas na língua, com identificação principalmente em células basais do epitélio escamoso estratificado (Fig.4). O linfonodo mesentérico foi o melhor órgão linfóide para o diagnóstico imuno-histoquímico (60/96). Células linfóides positivas foram identificadas em baixo a moderado número, com predomínio da região folicular sobre as regiões parafolicular ou medular (Fig.5). A medula óssea apresentou baixo número de casos com marcação positiva (47/91). A marcação do parvovírus nas placas de Peyer revelou poucos resultados positivos (38/84) e com raras células linfóides marcadas. No timo, baixa porcentagem de positividade foi observada. Marcações quando presentes se localizaram na região cortical deste órgão linfóide e geralmente com grau de marcação pouco intensa. Entre os órgãos testados, o baço apresentou o menor número de marcação positiva (42/96) (Fig.6).

A análise estatística demostrou que o intestino delgado apresentou a maior razão de chances (Odds ratio) de obtenção de marcação positiva para CPV na imuno-histoquímica (Fig.7). Comparando a razão de chances do intestino delgado com a da tonsila epitelial. Observa-se que o intestino delgado tem uma razão de chances $95 \%$ maior de apresentar resultado imuno-histoquímico positivo que as células epiteliais da tonsila. Entretanto, menor razão de chances foi obtida em órgãos linfóides, uma vez que a chance de obter marcação positiva no linfonodo é quatro vezes menor quando comparado ao intestino delgado. A freqüência de segmentos intestinais positivos para CPV com autólise foi de $59 \%$, enquanto que nos tecidos sem autólise a marcação positiva foi obtida em 81\% (Quadro 3). Analisando estes resultados, observamos que ocorreu uma fraca associação entre a autólise e a positividade da imuno-histoquímica. Cortes histológicos de intestinos que apresentam alterações autolíticas possuem 0,33 vezes menos chance de apresentar resultado positivo na imuno-histoquímica quando comparada a fragmentos de intestino sem autólise.

\section{DISCUSSÃO}

O presente estudo descreve os achados macroscópicos, histopatológicos e imuno-histoquímicos de cães infectados naturalmente pelo parvovírus canino. A média e o intervalo de idades dos casos analisados são similares aos observados por outros autores (Pletcher et al. 1979,

Quadro 3. Resultado comparativo do teste imunohistoquímico realizado em cortes de intestino com e sem autólise $^{a}$

\begin{tabular}{lcccc}
\hline \multirow{2}{*}{ Autólise } & \multicolumn{2}{l}{ Imuno-histoquímica do intestino } & Total & Freqüência \\
\cline { 2 - 3 } & Positivo & Negativo & & \\
\hline Presença & 10 & 7 & 17 & $59 \%$ \\
Ausência & 64 & 15 & 79 & $81 \%$ \\
Total & 74 & 22 & 96 & \\
\hline
\end{tabular}

a Teste exato de Fischer, $p=0.06$; OR = 0,33 (IC 95\%; 0,10-1,17). 

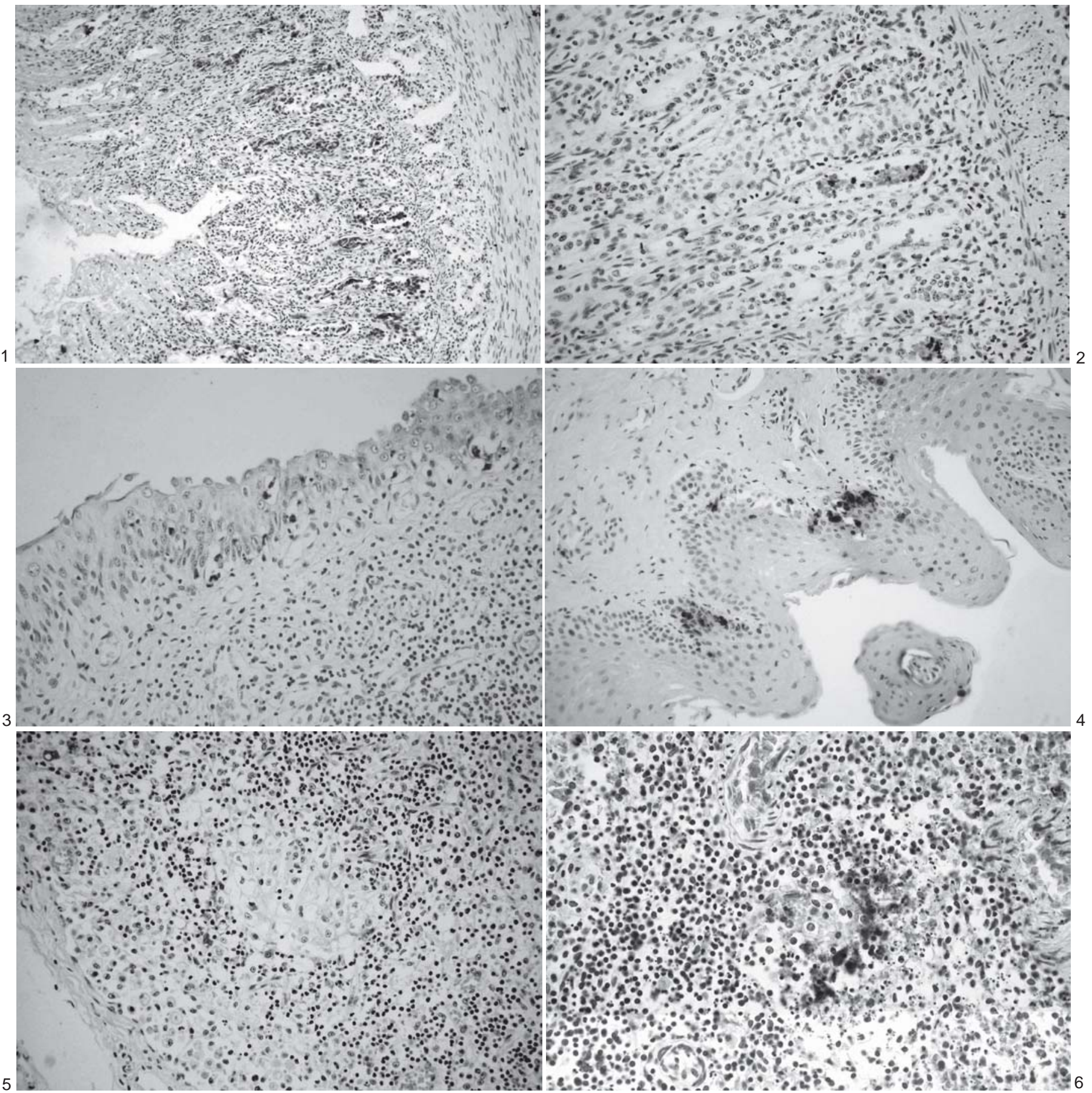

Fig.1. Marcação positiva de CPV no intestino delgado, marcando células epiteliais e células descamadas, principalmente na base das vilosidades. Imuno-histoquímica (IHQ) pelo método streptavidina-biotina-peroxidase, obj.20x.

Fig.3. Maior marcação de células positivas para CPV no epitélio da tonsila do que em tecidos linfóides. IHQ pelo método streptavidina-biotina-peroxidase, obj.40x.

Fig.5. Linfonodo mesentérico apresentando rarefação linfóide de centros foliculares com marcação positiva de células linfóides para CPV da periferia de folículos. IHQ pelo método streptavidina-biotina-peroxidase, obj.40x.

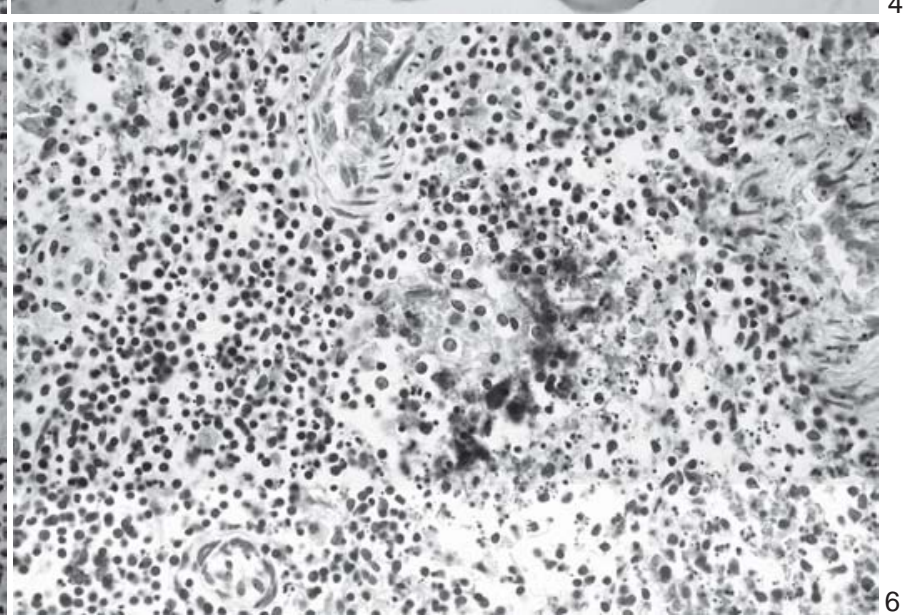

Fig.2. Identificação positiva de CPV em maior quantidade nas células descamadas de vilosidades intestinais. IHQ pelo método streptavidina-biotina-peroxidase, obj.40x.

Fig.4. Identificação positiva de CPV no epitélio escamoso estratificado da língua, com predomínio da marcação em células basais. IHQ pelo método streptavidina-biotinaperoxidase, obj.40x.

Fig.6. Baço com necrose linfóide e marcação para CPV em folículos. IHQ pelo método streptavidina-biotina-peroxidase, obj.40x. 


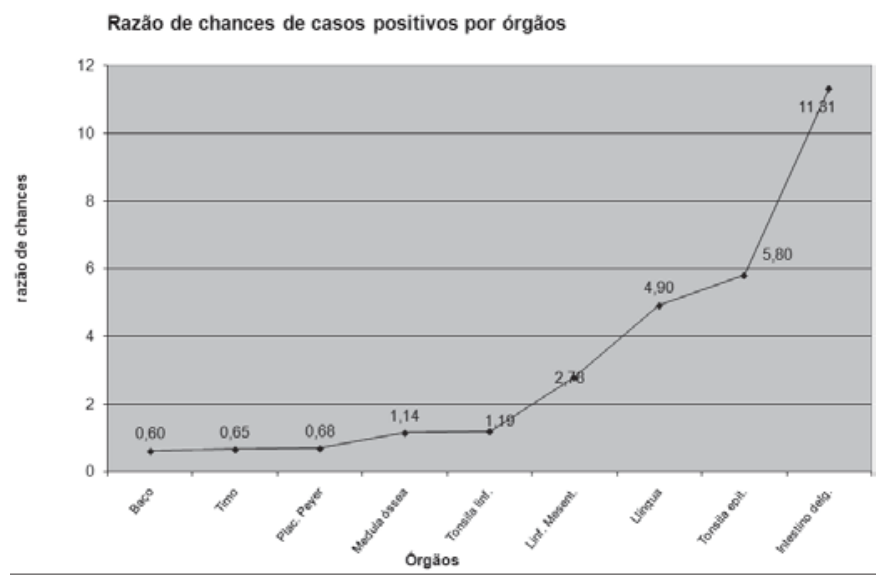

Fig.7. Gráfico com a razão de chances (Odds ratio) de positividade para cada órgão testado pela técnica de imunohistoquímica para detecção de CPV.

Harcourt et al. 1980). Na observação das raças necropsiadas no estudo, constatou-se que cães Rottweiler são encontrados como a segunda raça mais acometida. Este resultado pode estar relacionado com a predisposição sugerida de maior risco de cães Rottweiler serem acometidos pela parvovirose canina (Glickman et al. 1985). Porém, nenhuma predisposição foi descrita nas raças Poodle e Shih-tzu. Neste estudo, as fêmeas foram mais acometidas 54\% (52/96), porém nenhuma predisposição por sexo pode ser relacionada com os casos de parvovirose canina (Hoskins 1997). Os achados macroscópicos e microscópicos observados em órgãos linfóides e no intestino delgado são descritos em inúmeros trabalhos sobre parvovirose canina (Cooper et al. 1979, Nelson et al. 1979, Macartney et al. 1984a). A microscopia dos órgãos demonstrou que os achados mais constantemente observados foram encontrados na tonsila, timo e baço como resultado da necrose linfóide provocada pelo parvovírus canino. A autólise intestinal observada em parte dos segmentos intestinais testados prejudicou a análise histopatológica, impossibilitando a caracterização de enterite necrótica num maior número de casos, lesão esta atribuída à infecção pelo parvovírus canino.

Embora os cães tenham apresentado lesões microscópicas sugestivas de infecção por CPV, a identificação viral em tecidos pela imuno-histoquímica não foi possível em todos os casos. Parte dos resultados negativos pode estar relacionada ao fato da imuno-histoquímica ser um teste altamente específico, porém pouco sensível (Van Maanen et al. 2004).

A avaliação imuno-histoquímica de tecido de cães demonstrou que o melhor órgão para a identificação do CPV foi o intestino delgado. Neste órgão, foi obtido um número maior de marcação positiva e uma maior quantidade de células marcadas. Com relação ao número de cortes intestinais onde o vírus foi detectado, resultado semelhante foi encontrado por Romero et al. (2007) com marcação em $76,67 \%$ dos animais testados. Através de estudos experimentais, o CPV foi identificado inicialmente na tonsila, timo, linfonodos retrofaríngeos e mesentéricos, e somente após a viremia o vírus foi observado no intestino delgado (Macartney et al. 1984b, Meunier et al. 1985). A identificação do CPV em células epiteliais intestinais somente ocorre no quinto ou sexto dia de infecção, com um número máximo de células infectadas no sétimo dia e diminuição da quantidade de células atingidas no oitavo e nono dia (Carman \& Povey 1985, Meunier et al. 1985). Meunier et al. (1985) observaram menor quantidade de células positivas após o sexto dia de infecção em placas de Peyer, linfonodos mesentéricos e timo. Baseando-se nestes resultados podemos sugerir que o intestino delgado é um dos últimos órgãos a ser afetado por este vírus, mantendo um número maior de células positivas para CPV no momento do diagnóstico. Em contrapartida, a imuno-histoquímica de tecidos linfóide revelou um menor número de cortes positivos para CPV e em geral com baixa quantidade de células linfóides marcadas. Com base nestes resultados e na observação desses outros autores, a rápida passagem do parvovírus canino em órgãos linfóides também pode ser sugerida.

Fraca associação entre autólise intestinal e o resultado imuno-histoquímico negativo de CPV foi observada no intestino delgado. Diversos trabalhos apontam que a autólise tecidual prejudica o teste de imuno-histoquímica (Thür et al. 1997, Arslan et al. 2004), principalmente na detecção de agentes virais (Ramos-Vara et al.1999). Entretanto, órgãos como língua e tonsila podem ser utilizados como tecidos auxiliares no diagnóstico de parvovirose canina principalmente, quando amostras de intestino delgado encontram-se autolisados. A utilização da língua para o diagnóstico da parvovirose canina também foi realizada em outros estudos, obtendo-se bons resultados na imuno-histoquímica para a identificação do CPV (Bauder et al. 2000, McKnight et al. 2007). Isto devido à alta taxa de mitose das células basais da língua para reposição do epitélio, favorecendo a multiplicação viral (Bauder et al. 2000). Concluímos que, a imuno-histoquímica deve ser considerada uma ferramenta importante no diagnóstico definitivo de parvovirose canina, especialmente em cortes histológicos com lesões intestinais inespecíficas devido à autólise tecidual. A dificuldade do diagnóstico por causa de autólise em lesões entéricas em rotina laboratorial é inevitável em animais de estimação. Adicionalmente, em casos onde o diagnóstico histológico ou imuno-histoquímico em tecido intestinal não for possível, a utilização da língua e do epitélio da tonsila podem auxiliar no diagnóstico pela melhor taxa de conservação no período post-mortem.

Agradecimentos.- Aos estagiários, funcionários e alunos pósgraduandos do Setor de Patologia Veterinária da UFRGS pela constante ajuda no desenvolvimento deste trabalho. À Coordenação de Aperfeiçoamento de Pessoal de Nível Superior (CAPES), pela concessão de bolsa de mestrado.

\section{REFERÊNCIAS}

Agungpriyono D.R., Uchida K., Tabaru H., Yamaguchi R. \& Tateyama S. 1999. Subacute massive necrotizing myocarditis by canine parvovirus type 2 infection with diffuse leukoencephalomalacia in a puppy. Vet. Pathol. 36:77-80. 
Appel M.J.G., Cooper B.J., Greisen H., Scott F. \& Carmichael L.E. 1979. Canine viral enteritis. I. Status report on corona- and parvo-like viral enteritides. Cornell Vet. 69:123-133.

Arslan A., Saglam Y.S. \& Temur A. 2004. Detection of rabies viral antigens in non-autolysed and autolysed tissues by using an immunoperoxidase technique. Vet. Rec. 155:550-552.

Bauder B., Suchy A., Gabler C. \& Weissenböck H. 2000. Apoptosis in feline panleukopenia and canine parvovirus enteritis. J. Vet. Med. B. 47:775-784.

Carman P.S. \& Povey R.C. 1985. Pathogenesis of canine parvovirus-2 in dogs: histopathology and antigen identification in tissues. Res. Vet. Sci. 38:141-150.

Cooper B.J., Carmichael L.E., Appel M.J.G. \& Greisen H. 1979. Canine viral enteritis. II. Morphologic lesions in naturally occuring parvovirus infection. Cornell Vet. 69:134-144.

Glickman L.T., Domanski L.M., Patroneck G.J. \& Visintainer F. 1985. Breed-related risk factors for canine parvovirus enteritis. J. Am. Vet. Med. Assoc. 187:589-594.

Hagiwara M.K., July J.R., Baccaro M.R. \& Angelo M.J.O. 1980. Enterite hemorrágica em cães associada à infecção por um parvovírus. Arqs Inst. Biológico, São Paulo, 47:47-49.

Harcourt R.A., Spurling N.W. \& Pick C.R. 1980. Parvovirus infection in a Beagle colony. J. Small Anim. Pract. 21:293-302.

Hoskins J.D. 1997. Update on canine parvoviral enteritis. Vet. Med. 92:694-709.

Jones T.C., Hunt R.D. \& King N.W. 2000. Moléstias causadas por agentes virais, p.266-270. In: (Ed.), Patologia Veterinária. 6aㅡ ed. Manole, São Paulo. 1415p.

MacArtney L., McCandlish I.A.P., Thompson H. \& Cornwell H.J.C. 1984a. Canine parvovirus enteritis 1: Clinical, haematological and pathological features of experimental infection. Vet. Rec. 115:201-210.

MacArtney L., McCandlish I.A.P., Thompson H. \& Cornwell H.J.C. 1984b. Canine parvovirus enteritis 2: Pathogenesis. Vet. Rec. 115:453-460.

Mason M.J., Gillett N.A. \& Muggenburg B.A. 1987. Clinical, pathological, and epidemiological aspects of canine parvoviral enteritis in an unvaccinated closed beagle colony: 1978-1985. J. Am. Anim. Hosp. Assoc. 23:183-192.
McCaw D.L. \& Hoskins J.D. 2006. Canine viral enteritis, p.63-73. In: Greene C.E. (Ed.), Infectious Diseases of the Dog and Cat. 2nd. ed. W.B. Saunders Elsevier, Philadelphia. 1387p.

McKnight C.A., Maes R.K, Wise A.G. \& Kiupel M. 2007. Evaluation of tongue as a complementary sample for the diagnosis of parvoviral infection in dogs and cats. J. Vet. Diagn. Invest. 19:409-413.

Meunier P.C., Glickman L.T., Appel M.J.G. \& Shin S.J. 1981. Canine parvovirus in a commercial kennel: Epidemiologic and pathologic findings. Cornell Vet. 71:96-110.

Meunier P.C., Cooper B.J., Appel M.J.G., Lanieu M.E. \& Slauson D.O. 1985. Pathogenesis of canine parvovirus enteritis: Sequencial virus distribution and passive immunization studies. Vet. Pathol. 22:617-624.

Nelson D.T., Eutis S.L., McAdaragh J.P. \& Stotz I. 1979. Lesions of spontaneous canine viral enteritis. Vet. Pathol. 16:680-686.

Pletcher J.M., Toft J.D., Frey R.M. \& Casey H.W. 1979. Histopathologic evidence for parvovirus infection in dogs. J. Am. Vet. Med. Assoc. 175: 825-828.

Ramos-Vara J., Segalés J., Duran C.O., Campbell K. \& Domingo M. 1999. Diagnosing infectious porcine diseases using immunohistochemistry. Swine Health Prod. 7:85-91.

Romero R.A.R., Aranda E.C., Godoy F.S. \& Watty A.D. 2007. Diagnóstico del parvovirus canino-2 (pcv-2) por inmunohistoquímica en perros domésticos. Vet. Méx. 38:41-53.

Svara T., Juntes P., Pogacnik M., Gombac M. \& Hostnik P. 2003. Immunohistochemical demonstration of parvoviral antigen in the organs of dogs with canine parvovirus. Slov. Vet. Res. 40:81-90.

Thür B., Hilbe M., Strasser M. \& Ehrensperger F. 1997. Immunohistochemical diagnosis of pestivirus infection associated with bovine and ovine abortion and perinatal death. Am. J. Vet. Res. 58:1371-1375.

Van Maanen C., Wouda W., Schares G., Von Blumröder D., Conraths F., Norton R., Williams D.J.L., Esteban-Redondo I., Ines E.A., Mattsson J.G., Björkman C., Fernández-García A., Ortega-Mora L.M., Müller N., Sager H. \& Hemphill A. 2004. A interlaboratory comparison of immunohistochemistry and PCR methods for detection of Neospora caninum in bovine foetal tissues. Vet. Parasitol. 126:351-364

Zee Y.C. \& MacLachlan N.J. 2004. Parvoviridae and circoviridae, p.305314. In: Hirsh D.C., MacLachlan N.J. \& Walker R.L. (Ed.), Veterinary Microbiology. 2nd ed. Blackwell, Ames, lowa. 536p. 